\title{
Correction to: Imaging of Spinal Infection
}

\author{
Mohamed Fethi Ladeb and Wilfred C. G. Peh
}

\section{Correction to: M. F. Ladeb, W. C. G. Peh (eds.), Imaging of Spinal Infection, Medical Radiology Diagnostic Imaging, https://doi.org/10.1007/978-3-030-70459-9}

The book was inadvertently published with an incorrect affiliation for all the authors in the following chapters,

Radiography and Computed Tomography of Spinal Infection

Magnetic Resonance Imaging of Spinal Infection

Nuclear Medicine Imaging of Spinal Infection

Imaging of Hematogeneous Pyogenic Spondylodiscitis

Imaging of Iatrogenic Spinal Infection

Imaging of Pyogenic Epidural Abscess

Diagnostic Algorithm of Spinal Infection

The incorrect affiliation has been deleted now.

The updated version of the book can be found at https://doi.org/10.1007/978-3-030-70459-9 